\title{
THE NUMERICAL SIMULATION OF STORM-SURGE AND COASTAL INUNDATION OF 2007 TYPHOON SEPAT
}

\author{
Yu-Hsien Lin ${ }^{1}$, Hwung-Hweng Hwung ${ }^{2 *}$, Ming-Chung Fang ${ }^{3}$, Ray-Yeng Yang ${ }^{4}$
}

\begin{abstract}
A comprehensive numerical model for simulating storm surge has been aimed at the middle-east Taiwan Strait, in which contains the Penghu Channel (PHC) and Changyun Rise (CYR). The simulation results can be used to understand the direct impact of storm surge on the interest area during typhoon invades. The case in this study is Typhoon SEPAT, which passed through central Taiwan in 2007. The transport characteristics through the Taiwan Strait under the influence of Typhoon SEPAT were analyzed using both field observations and numerical simulations during the typhoon period. The results show that storm surge did not respond to the southerly winds but the northerly winds, in contrast to the wind waves. According to the influence of dynamical forces on the storm surge in the Taiwan Strait, the atmospheric pressure gradient is found to be the dominant force of the coastal inundation during the typhoon event. By comparing with the numerical experiment, the Coriolis force is found to have a negative contribution to the storm surge generation in the Taiwan Strait.
\end{abstract}

Keywords: storm surge, inundation, typhoon, Taiwan Strait, SEPAT

\section{INTRODUCTION}

Taiwan, which is located on the west side of the Pacific Ocean, is usually invaded by typhoons during summer and autumn seasons. A long, shallow channel, which connects the East China Sea (ECS) and South China Sea (SCS) on the continental Shelf of the West Pacific Ocean, is Taiwan Strait. It is about $350 \mathrm{~km}$ long, $180 \mathrm{~km}$ wide with the averaged water depth of $60 \mathrm{~m}$ except over the deep Penghu Channel (PHC) next to the middle-west side of Taiwan Island (Wu et al., 2007). The historical records from Central Weather Bureau (CWB) of Taiwan indicated that there were totally 393 typhoons striking Taiwan from 1897 to 2007 . The recurrence probability of typhoon events invading Taiwan is about 3.96 per year. In 2007, there were totally up to five typhoons striking Taiwan during the period from August to October.

Numerical studies (i.e. Jelesnianski et al., 1984; Jelesnianski, 1972) of storm surge began in 1970s for predicting the open-coast storm surge elevation by National Oceanic Atmospheric Administration (NOAA, US). Subsequently, Xie et al., 2004 suggested a numerical model that incorporates mass conservation and flexibility to choose inundation speed on the basis of 3D flow field. Furthermore, the multi-grid method is used in the storm surge model (Hsu et al., 2005) for increasing the horizontal resolution in a sub-region of the model domain, without incurring the computational expense of high resolution over the entire model domain. However, the inundation records that can be used to validate the inundation prediction of the model are still very scanty.

To shed more light on the storm surge variation induced by typhoons in the Taiwan Strait, a case study of typhoon SEPAT in 2007 including the field observations near Mailiao Harbor (as shown in Figure 1) and model results with systematic numerical experiments were considered in this research. In this paper, the numerical model, COMCOT-S (COrnell Multi-grid Coupled Tsunami model for Storm-surge, (Wang and Liu, 2007) adopts the explicit staggered leap-frog finite difference scheme in a multigrid system to solve the nonlinear shallow water wave equation in a spherical coordinate. Since this study was focused on the typhoon-induced flooding heights along the coasts of Taiwan Strait, the inundation calculation is obtained according to the moving boundary scheme available in the model.

\footnotetext{
${ }^{1}$ National Cheng-Kung University, vyhlin@mail.ncku.edu.tw

${ }^{2}$ National Cheng-Kung University, hhhwung@mail.ncku.edu.tw

${ }^{3}$ National Cheng-Kung University, fangmc@mail.ncku.edu.tw

${ }^{4}$ National Cheng-Kung University, ryyang@mail.ncku.edu.tw
} 

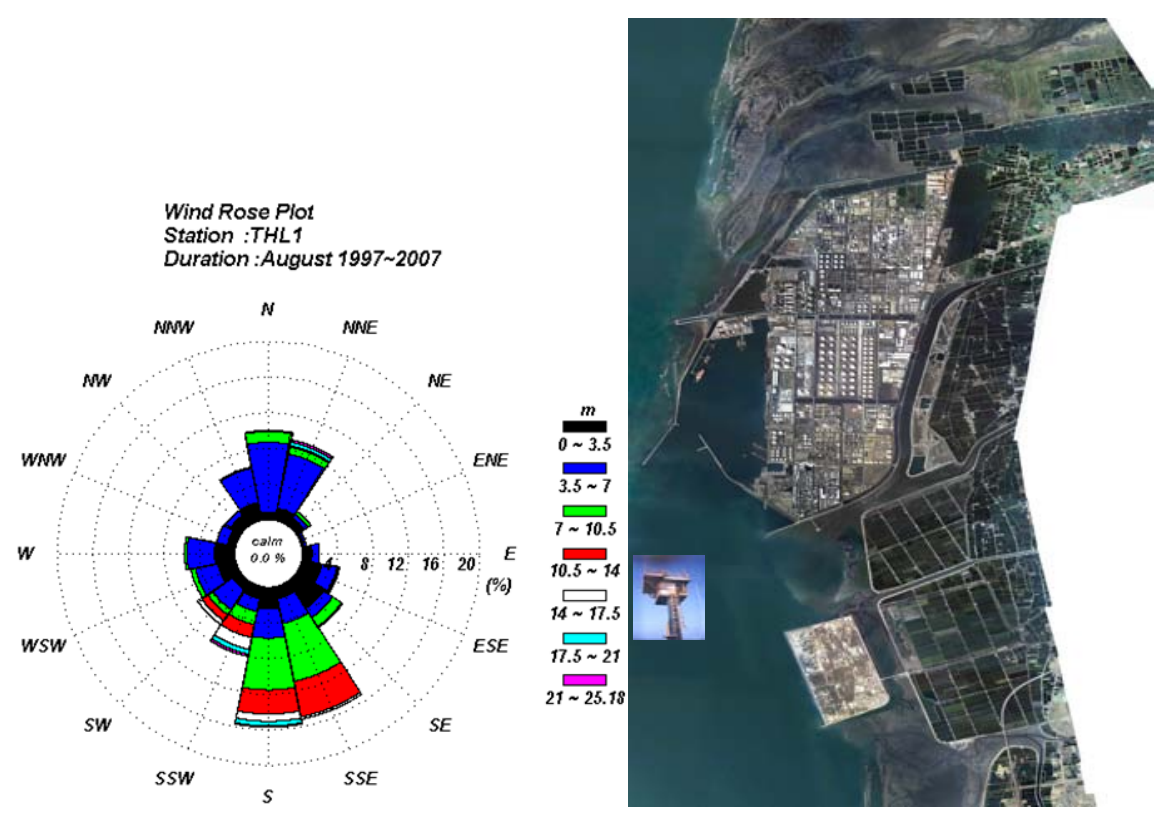

Figure 1. The satellite image around the area of the Mailiao Harbor. The pile denotes the location of the measurement station (THL1). The wind-rose plot presents the statistical records at THL1 station $\left(120.14^{\circ} \mathrm{E}, 23.76^{\circ} \mathrm{N}\right)$ from 1997 to 2007 on August.

\section{MODEL DESCRIPTION}

The hydrodynamic model implemented in this study adopts a spherical coordinate in the multi-grid system. In COMCOT-S, the Non-Linear Shallow water Wave equation (NLSW, hereinafter) can be assigned to each specific sub-level grid and be solved by the staggered leap-frog finite difference scheme. The sub-level grid regions are dynamically connected. In the largest grid (main layer), the earth rotation is relatively prominent and the local water depth in the open ocean is much larger than the propagating wave amplitude. Thus, the nonlinear advective terms and the bottom friction terms can be neglected in this situation. However, as the wave propagates over a continental shelf and approaches coastal regions, the shoaling effect would be increasingly significant. In that case, the nonlinear advective term and bottom frictional term become prominent during the simulation procedure, while the significance of the Coriolis force diminishes. The governing equations, dynamic forcing of the model and the numerical scheme will be described in this section.

Explicit leap-frog finite difference scheme has been adopted to solve the NLSW in the previous literatures (Cho, 1995; Wang and Liu, 2007). The nonlinear advective terms are discretized with an upwind scheme. In general, the upwind scheme is considerably stable and produces some numerical dissipation. But if the velocity gradient in the fluid field is not too steep and if the stability criterion (Imamura et al., 1988), $\Delta \mathrm{x}=(4 \mathrm{~h}+$ $\left.\mathrm{gh}(\Delta \mathrm{t})^{0.5}\right)^{0.5}$, is satisfied, upwind formulation is preferred for nonlinear advective terms. The linear terms of the governing equations are discretized by the leap-frog finite difference scheme, as well.

By using multi-grid system, COMCOT-S is capable of simultaneously calculating the wave propagation in deep ocean and the inundation in the coastal areas of interest. In the multi-grid system, the finer grids adopt a smaller grid size and time step and are nested inside a larger grid. During the simulation procedure, the finer grids will be assigned to resolve wave profiles in shallow water regions. Therefore, when the water depth varies within the largest layer, it might be desirable that different grid size and time step size be employed in different sub-grids. At the beginning of each time step, 
along the boundary of two different grids, the volume flux is interpolated from the larger grid into the finer grid. The water surface elevations and the volume fluxes in the finer grids are calculated and the resulting free-surface elevations are averaged to update those values in the coarser grids. In addition, the volume fluxes in the coarser grids can be updated. The advantage of multi-grid system is that we can simulate the dynamics of storm-induced currents in the nearshore regions with high spatial and temporal resolutions, and can maintain a high computational efficiency, simultaneously.

A dynamically coupled system of nested grids was employed to simulate the storm surge propagation from the Pacific Ocean toward the Taiwan Strait with the flow variation under consideration. Table 1 gives the spatial extent and the resolution of the coarser and finer grids as well as the governing equations used. The outer domain (Fig. 2), covered with the largest grid size (main grid, L1 hereinafter), ranges from $115^{\circ} \mathrm{E}$ to $135^{\circ} \mathrm{E}$ in longitude and from $15^{\circ} \mathrm{N}$ to $29^{\circ} \mathrm{N}$ in latitude, with a grid resolution of 1' $(\sim 1.8 \mathrm{~km})$. The bathymetry and land elevation for L1 were extrapolated and obtained from ETOPO1 data and 2007 geodetic survey data of industrial park of an offshore-island in Yunlin County, with grid dimension 1201×841.

\begin{tabular}{|c|c|c|c|c|}
\hline \multicolumn{4}{|c|}{ Table 1. Model information of the nested grids implemented in the numerical simulations } \\
\hline \multirow{2}{*}{ Grid No. } & Extent of Grid (Geographic, WGS84) & & \\
\cline { 2 - 5 } 1 & Longitude & Latitude & Grid Dimension & Grid Resolution \\
2 & $115-135$ & $15-29$ & $1201 \times 841$ & 1 min $(\sim 1.8 \mathrm{~km})$ \\
& $116.5-121$ & $23-25$ & $1201 \times 841$ & $0.2 \mathrm{~min}(\sim 360 \mathrm{~m})$ \\
\hline
\end{tabular}

The bathymetric data for $\mathrm{L} 2$, as indicated in Fig. 3, ranges from $116.5^{\circ} \mathrm{E}$ to $121.0^{\circ} \mathrm{E}$ in longitude and from $23.0^{\circ} \mathrm{N}$ to $25.0^{\circ} \mathrm{N}$ in latitude, with a grid resolution of $0.2^{\prime}(\sim 360 \mathrm{~m})$. The bathymetry data of L2 were interpolated from ETOPO1 and extrapolated from 2007 bathymetry survey data of industrial park of an offshore-island in Yunliin County as well, with a grid dimension of $1351 \times 601$. According to the suggestion by the author (Flather, 1976), the depth-averaged velocity on open boundaries is

$$
\overline{u_{n}}=\overline{u_{n}^{0}}+\sqrt{\frac{g}{H}}\left(\zeta-\zeta^{0}\right)
$$

where $\overline{u_{n}}$ is the depth-averaged velocity normal to open boundaries of COMCOT-S and $\overline{u_{n}^{0}}$ is the current input on the open boundaries at time $t$. The modeling surge elevation $\zeta^{0}$ is located on the open boundaries of COMCOT-S. Furthermore, the zero normal gradient condition for sea grids is used on all open boundaries.

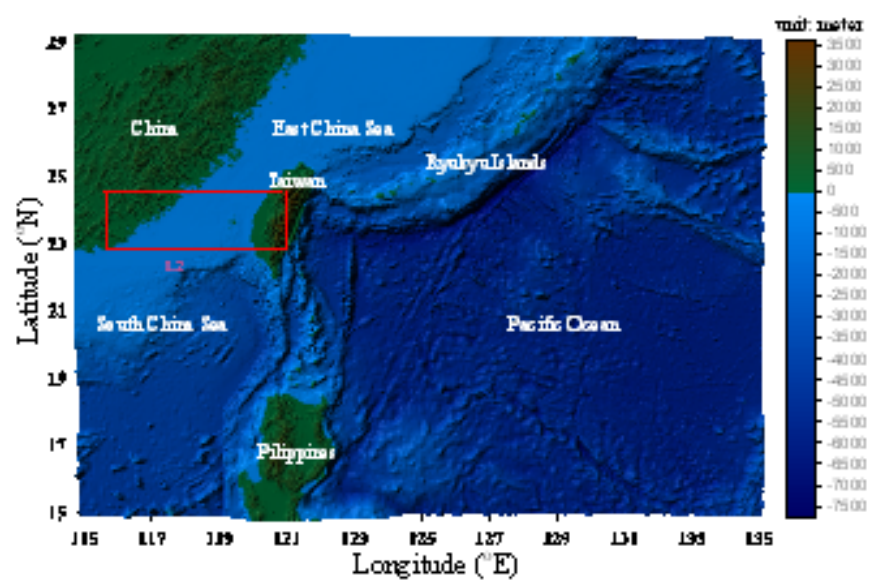

Figure 2. Model domains for the ocean (L1) and coastal (L2) grids with topographic and bathymetric contours in meters. 


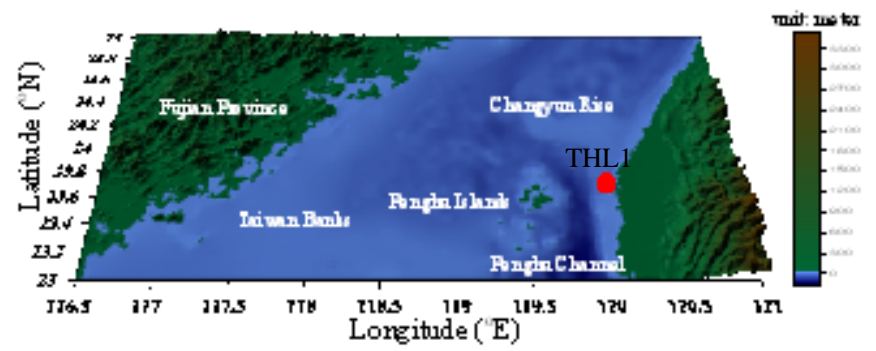

Figure 3. The perspective view of L2 grid with topographic and bathymetric contours in meters.

\section{FIELD MEASUREMENT}

The Penghu Channel (PHC, hereinafter) is adjoining to the west side of Yunlin coasts, with the Changyun Rise (CYR) blocking on the north side (Figure 2). Measurements of sustained winds and wave heights were sparse in this area as well as the current measurements. During the period of Typhoon SEPAT passage (16 19 August, 2007), a series of well-documented records of real-time data were measured by the observational platform (THL1, shown in Figure 1) of Tainan Hydraulics Laboratory, which was situated on the southwest side of Mailiao Harbor, Yunlin County. The information of sustained winds were recorded by a wind monitor, Young 05103 (Table 2), which was mounted $12 \mathrm{~m}$ above the sea level over the platform. The interval of wind measurement is 3 minutes. The current data were obtained from the current self-recording type instrument, Valeport 308 (Table 3), which was deployed $-13 \mathrm{~m}$ beneath the mean sea level. Each data interval of currents is 5 minutes for data acquisition. Furthermore, the significant wave height, measured by the pressure sensor above the sea bed, is based on the Rayleigh distribution with its corresponding peak period for 20 min at 1-hr intervals

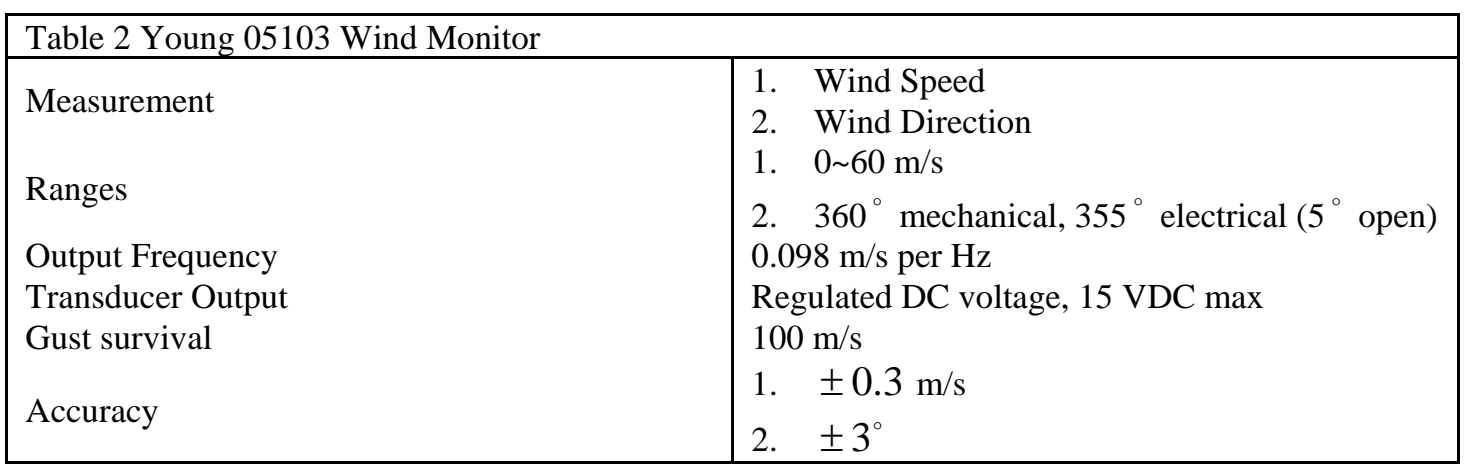

\begin{tabular}{|c|c|c|c|c|}
\hline $\begin{array}{l}\text { Sensor } \\
\text { Specifications }\end{array}$ & Type & Range & Accuracy & Resolution \\
\hline Speed & Impeller & $0.03 \sim 5 \mathrm{~m} / \mathrm{s}$ & $0.15 \sim 5 \mathrm{~m} / \mathrm{s}<1.5 \%$ of reading & $0.01 \mathrm{~m} / \mathrm{s}$ \\
\hline Direction & $\begin{array}{l}\text { Flux gate } \\
\text { compass }\end{array}$ & $0^{\circ} \sim 360^{\circ}$ & $\pm 2^{\circ}$ & $0.25^{\circ}$ \\
\hline
\end{tabular}

After data acquisition is over, each data set would be subsequently stored on the hard disk. The data transmission is based on GPRS (General Packet Radio Service), which was deployed by Tainan Hydraulics Laboratory. Consequently, the digital signals would be transmitted back to the information center at Tainan Hydraulic Laboratory for further processing.

At the local station, the tidal components of ocean currents were analyzed via a least square fit method. Then the tidal components were removed from the original data. The filtered signals via a nonlinear second power function fit method was performed for the measured data after removing the observational noises. 


\section{RESULTS AND DISCUSSION}

Typhoon SEPAT was a powerful category 4 typhoon on the Saffir-Simpson scale, one level below the maximum strength of super typhoon. As Typhoon SEPAT made landfall on Taiwan during the period from 05:40 LST 18 August to 11:00 LST 18 August, it caused severe disasters on Taiwan and cut power supplies to more than 70,000 homes. Warnings were frequently issued about the larger waves in the Taiwan Strait and coastal flooding of low-lying lands.

Figure 4 shows the track of Typhoon SEPAT and the satellite image as this lowpressure system becomes a typhoon. In this study, COMCOT-S was used to calculate the atmospheric pressure and sea surface wind stress for the subsequent simulation of volume fluxes and surge heights. The model includes the multi-grid system with two different grid resolutions and a function of moving boundary scheme. COMCOT-S requires four input parameters, such as the location and pressure of storm center, the radius of the maximum winds, and the ambient pressure. All the necessary parameters mentioned above were acquired from CWB. The atmospheric pressure and wind fields were calculated at 3-hourly interval by COMCOT-S. Subsequently, the numerical model was driven for 60 hours with 1 second time-step size using the atmospheric pressure and wind data as driven inputs. Consequently, the storm-surge simulation of Typhoon SEPAT was simulated for a 75-hours ( -3.125 day) period starting 17:00 LST 16 August.
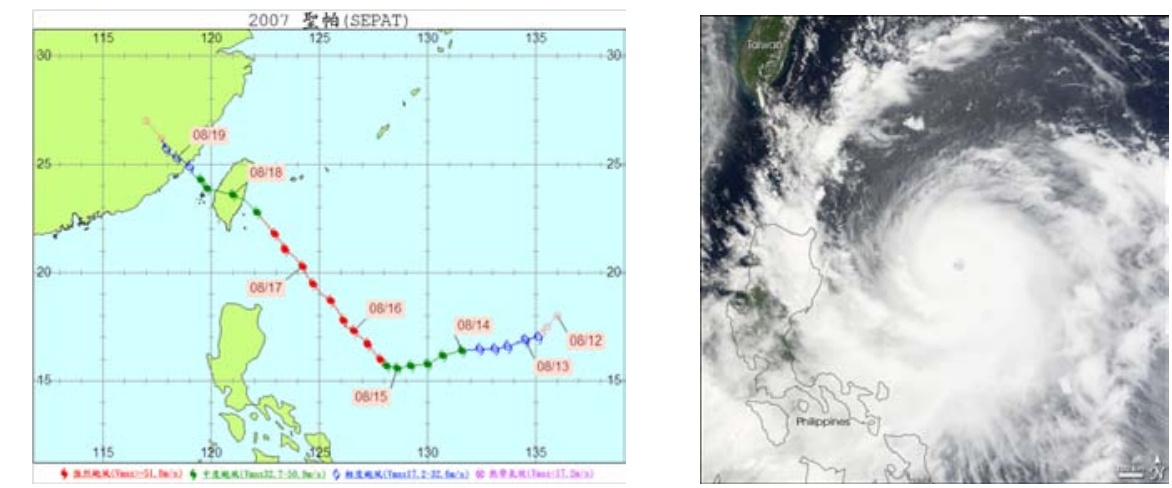

Figure 4. (Left) The historical track of Typhoon SEPAT (reprinted from the Central Weather Bureau); (Right) the satellite image of Typhoon SEPAT at 17:00 LST 16 August.

The left panel of Figure 5 shows comparisons between observations performed at the THL1 station near the Mailiao Harbor and the modeling wind data in the longitudinal and latitudinal directions, respectively. The correlation coefficient $(\mathrm{Cr})$ value between their wind speeds in the longitudinal direction exceeds 0.55 while the root-meansquare error is $3.12 \mathrm{~m} / \mathrm{s}$. For the wind components in the latitudinal direction, the $\mathrm{Cr}$ is 0.81 and the RMS error is $8.74 \mathrm{~m} / \mathrm{s}$. In general, the simulated wind data compare well with the field observations in this sea area, and the wind components in the latitudinal direction shows better comparisons than those in the longitudinal direction. In the right panel of Figure 5, the time series of storm surge of both observed and numerical results are illustrated with the wind wave heights. The results show that the curves of numerical and observed surge heights were nearly coincident. Although the peak of numerical results agrees pretty well with the observations, the time lag between the peaks of the storm surge and the wind wave heights is nearly $16 \mathrm{hrs}$. This is due to the fact that the surge heights are highly sensitive to the northerly winds; whereas the wind wave heights are affected by the southerly monsoon winds with the decrease of typhoon winds. Both the $\mathrm{Cr}$ values between surge heights of simulations and observations are found to exceed 0.9. For the RMS error of surge heights, the result appears the value of $0.14 \mathrm{~m}$. 

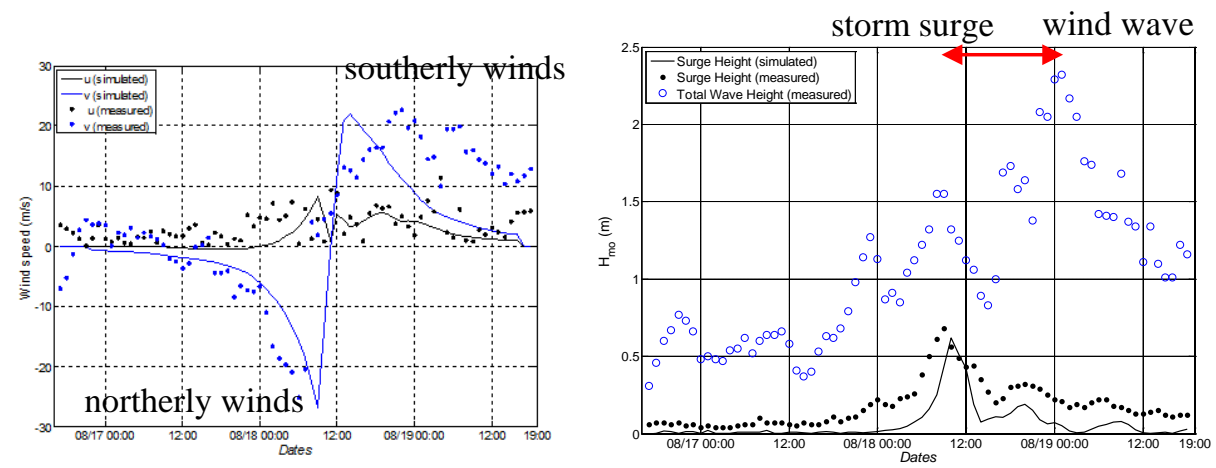

Figure 5. Comparisons of THL1 observations and model simulation for (left) the wind data; and for (right) the wave heights.

Figure 6 indicates the distribution of current vector fields in the Taiwan Strait with respect to the surface elevation of storm surge computed from COMCOT-S during the period from 06:00 LST 18 August to 02:00 LST 19 August. The top panel on the left hand side of Figure 6 shows that typhoon induced currents mainly moved southwestward along west Taiwan coasts, passed through the CYR and then entered the PHC, the major pathway by which the southward flow enters the SCS. The surface elevation in the Taiwan Strait is found to be less affected by the storm surge even if the typhoon center made landfall on the east coast of Taiwan.

The middle panel on the left hand side of Figure 6 shows that the location of typhoon center was presently at the estuary of Zhuoshui River. The storm induced current attains the maximum value of $0.89 \mathrm{~m} / \mathrm{s}$, in which the location is between the CYR and the PHC. The contour of storm surge oscillation presents that the storm surge induces a considerable amount of water along the western coast of Taiwan.

As Typhoon SEPAT moved close to the Quanzhou City, as shown in the bottom panel on the left hand side of Figure 6, it is interesting to find that the flow pattern in the Taiwan Strait turned northward principally. In addition, the formation of an anticyclonic eddy was well developed in the north reach of the Taiwan Strait, which is near to the northwest side of the CYR. Wu et al., 2007 suggested that the ocean currents passing through the Taiwan Strait in winter will also induce an anticyclone due to the existence of the CYR. Meanwhile, it is seen that the confluence of northward and southward currents will complicate the flow pattern in the middle reach of the Taiwan Strait.
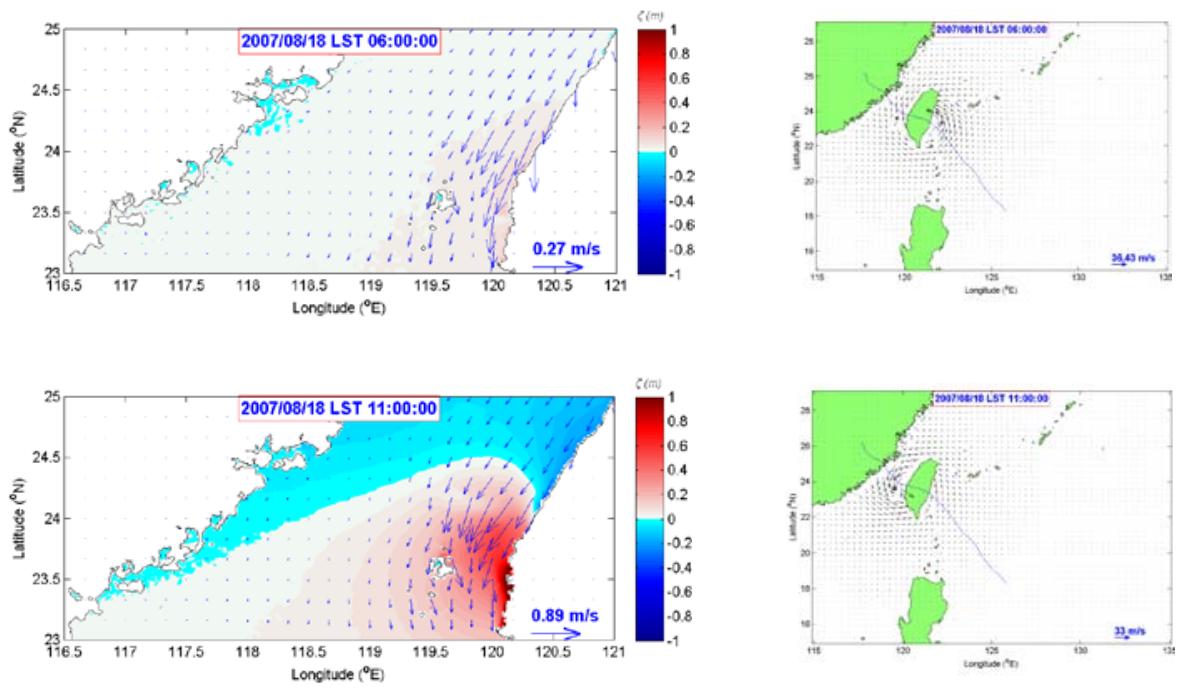

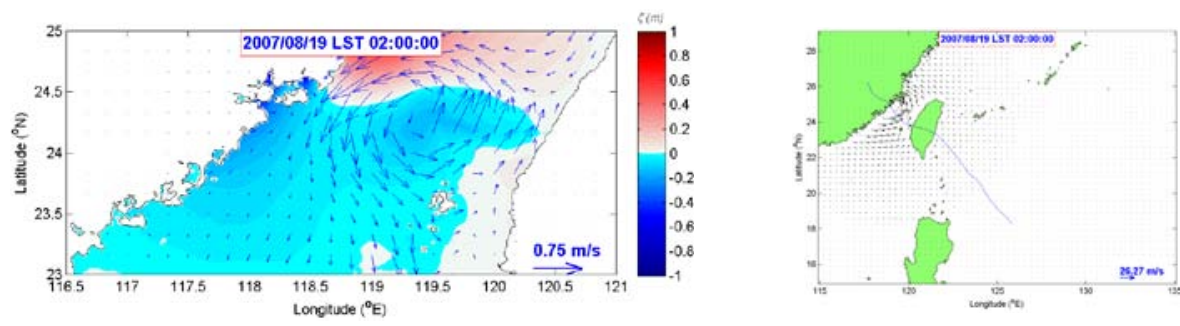

Figure 6. On the left hand side, the diagrams indicate the storm surge oscillations with the storm induced currents at three different landing locations: (top) the estuary of Siouguluan River, (middle) the estuary of Zhuoshui River, and (bottom) Quanzhou City, China. On the right hand side, the diagrams denote the corresponding wind vector distributions.

The panels on the left hand side of Figure 7 present the numerical results without the contribution of the Coriolis force. It is evident that the Coriolis force actually made negative contribution to the storm surge elevation and the currents in the Taiwan Strait. Besides, the flow reversal would not occur in the PHC without the contribution of the Coriolis force. More specific dynamic analysis should be carried out to understand this behavior in the future.
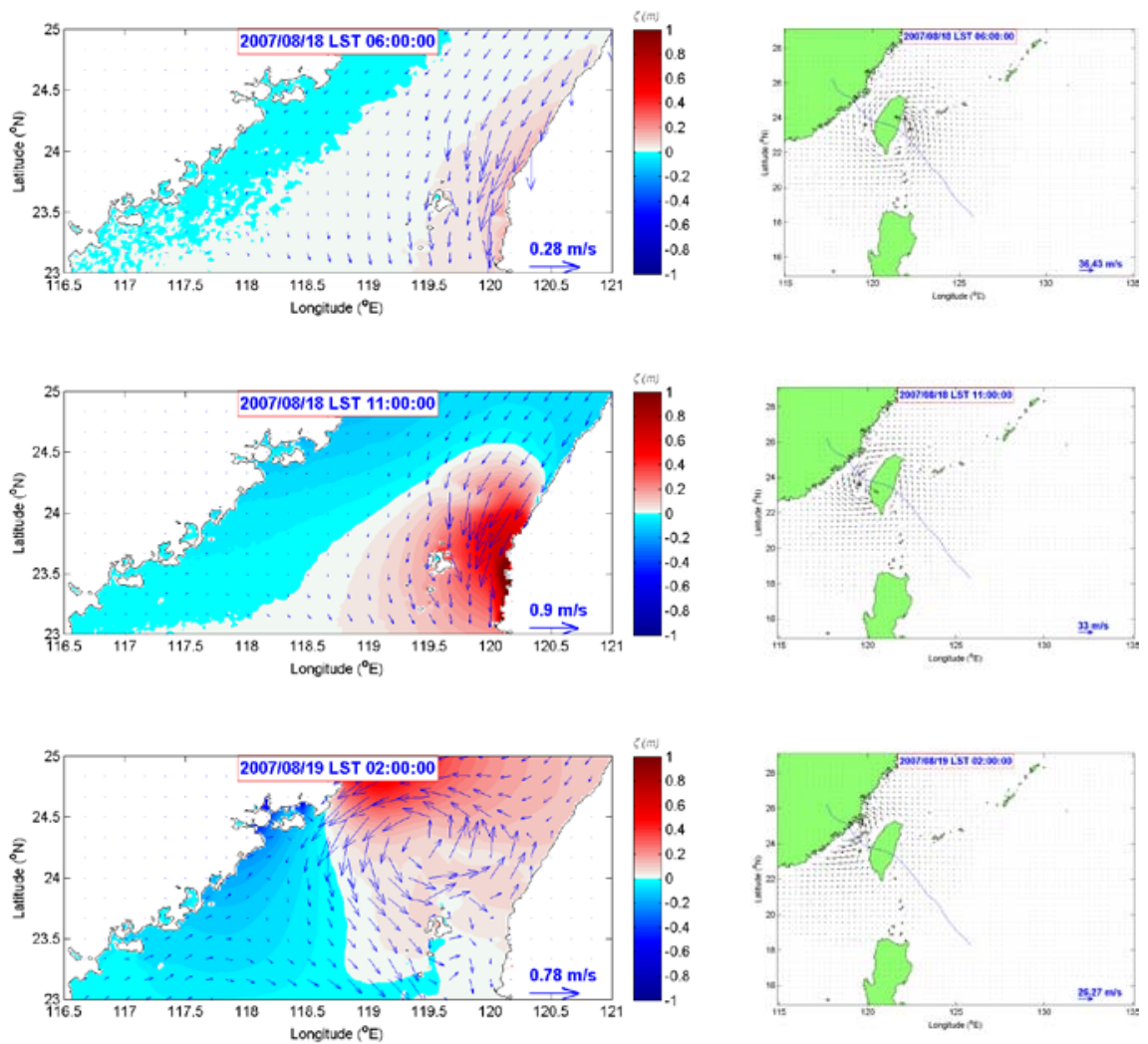

Figure 7. The same as in Figure 6, but without the contribution of the Coriolis force.

Figure 8 shows the maximum inundation and ebb depths on both sides of the Taiwan Strait as Typhoon SEPAT passed through the Taiwan Strait. The results indicate that typhoon-induced inundation is very sensitive to the typhoon-tracks even though the low-pressure system decreased its intensity and weakened the wind speeds. Although it is not shown here, our model results indicate that the atmospheric pressure gradient is the predominant factor of storm induced flooding while the typhoon passes through the Taiwan Strait. 

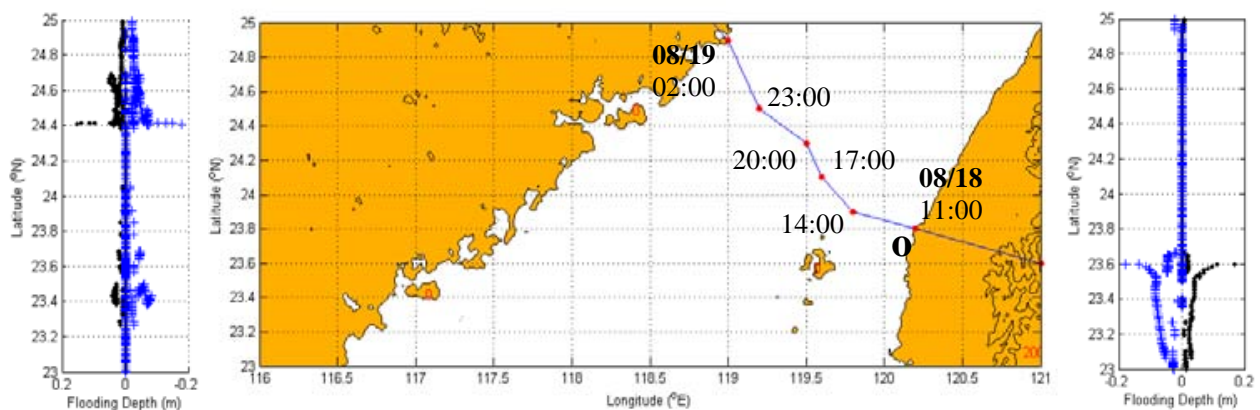

Figure 8. The maximum flooding ( () and ebb depths $(+)$ during the passage of Typhoon SEPAT over the Taiwan Strait in the nested grid. "o" marks the location of THL1 station.

\section{SUMMARY}

By conducting the numerical model, COMCOT-S, the storm-induced currents and the surge height variation in the Taiwan Strait during the period of Typhoon SEPAT are presented in this study. The results show that the storm surges were highly sensitive to the northerly winds; whereas the wind waves were subjected to the southerly winds during the passage of Typhoon SEPAT in the Taiwan Strait. An evident flow reversal occurred in the PHC as typhoon center made landfall on the mainland China. However, it did not happen to the case without the contribution of the Coriolis force. Finally, the results appear that the peaks of the flooding heights on both sides of the Taiwan Strait are highly correlated with the typhoon tracks, and that the pressure gradient is the predominant force on the variation inundation levels.

\section{ACKNOWLEDGMENTS}

This work is sponsored by National Science Council NSC 98-2811-E-006-046. The authors are thankful to Tainan Hydraulics Laboratory for providing the valuable field data.

\section{REFERENCES}

Cho, Y.S., 1995. Numerical simulations of tsunami and runup. Ph.D thesis Thesis, Cornell University. Flather, R.A., 1976. A tidal model of the north-west European continental shelf. Memor. Soc. Royal Sci., 6: 141-164.

Hsu, T.-W., Ou, S.-H. and Liau, J.-M., 2005. Hindcasting nearshore wind waves using a FEM code for SWAN. Coastal Engineering, 52: 177-195.

Imamura, F., Shuto, N. and Goto, C., 1988. Numerical simulation of the transoceanic propagation of tsunamis, Sixth Congress of the Asian and Pacific Regional Division, Int. Assoc. Hydraul. Res., Kyoto, Japan.

Jelesnianski, B.R., Chen, J., Shaffer, W.A. and Gilad, A.J., 1984. SLOSH: A hurricane storm surge forecast model, Mar. Technol. Soc., Washington, D. C.

Jelesnianski, C.P., 1972. SPLASH (Special program to List Amplitudes of Surges From Hurricanes), NOAA Tech. Memo. NWS TDL-46, Natl. Oceanic and Atmos. Admin., Silver Spring, Md.

Wang, X.M. and Liu, P.L.-F., 2007. Numerical simulations of the 2004 Indian ocean tsunamis - coastal effects. Journal of Earthquake and Tsunami, 1(3): 273-297.

Wu, C.-R., Chao, S.-Y. and Hsu, C., 2007. Transient, seasonal and interannual variability of the Taiwan Strait current. J. Oceanogr., 63: 821-833.

Xie, L., Pietrafesa, L. and Pen, M., 2004. Incorporation of a massconserving inundation scheme into a three-dimensional storm surge model. J. Coastal Res., 20: 1209-1223. 